higher education level, accept the intervention and different interventions were had a higher probability of using CRS, in which, the probability of intervention group tending to use CRS was significantly higher than the control group (biomechanical visualization $(\mathrm{OR}=2.57,95 \% \mathrm{CI}=1.72-3.85)$, education $(\mathrm{OR}=2.27,95 \% \mathrm{CI}=1.52-3.39), \quad$ behavioral education $(\mathrm{OR}=2.01,95 \% \mathrm{CI}=1.35-3.02))$, but there was no significant difference in the pairwise comparisons between the intervention groups. The ratings on child passenger safety knowledge and attitude increased significantly in both intervention groups $(\mathrm{P}<0.001)$ but remained unchanged in the control group after the intervention, the ratings are higher in biomechanical visualization intervention group than the education intervention group $(\mathrm{p}<0.05)$.

Conclusions Both parent-based child restraint system intervention helped to promote the parents' knowledge, attitude, and use of CRS. Biomechanical visualization could be an effective intervention to improve the use of CRS in the future.

\section{P5.012 A TIME-SERIES STUDY OF CHILD PASSENGER SAFETY IN SHANTOU, CHINA}

Liping Li*, Shuzhen Yan. Injury Prevention Research Center, Shantou University Medical College, Shan Tou, China

10.1136/injuryprev-2021-safety.232
Objective To explore the prevalence of child passenger safety behaviors and safety restraint use when children were riding so as to promote the use of child restraint system (CRS) in Shantou, China.

Methods Four cross-sectional studies were conducted in 2012, in 2015, in 2017 and in 2019. Hospitals, kindergartens, primary and secondary schools, highway toll stations were randomly selected as roadside observation sites. Data were collected on the use of safety restraint measures for children aged 17 and younger in the urban area of Shantou, China.

Results From 2012 to 2019, child passenger safety behaviors increased. The rate of safety restraints use increased from $9.6 \%$ in 2012 to $22.6 \%$ in 2019 ( $\mathrm{P}<0.001$ ), among which the rate of CRS use increased from $0.7 \%$ in 2012 to $8.2 \%$ in 2019 ( $\mathrm{P}<0.001)$, the rate of seatbelt use increased from $8.9 \%$ in 2012 to $14.4 \%$ in 2019 ( $\mathrm{P}<0.001$ ). The proportion of children sitting in the front row decreased from $30.3 \%$ in 2012 to $10.2 \%$ in 2019 ( $\mathrm{P}<0.001$ ). The percentage of children sitting on an adult's legs decreased from $16.7 \%$ in 2012 to $8.2 \%$ in 2019 ( $\mathrm{P}<0.001)$.

Conclusion From 2012 to 2019, the rate of CRS use and child passenger safety behaviors increased in Shantou, China. However, the CRS usage rate is still low. Corresponding measures need to be taken to ensure the safety of children when riding in the future. 